\title{
Insulin Sensitivity and Resistance in Infertile Women with Polycystic Ovary Syndrome
}

\author{
Havagiray R Chitme ${ }^{1 *}$, Eman Al Azawi ${ }^{2}$, Anfal Mohammed Al Abri ${ }^{1}$, Buthina Mohammed Al Busaidi ${ }^{1}$, Zamzam \\ Khamis Al Abdul Salam¹, Maisa Mosa Al Taie ${ }^{1}$ and Saja Khamis Al Harbo ${ }^{1}$
}

${ }^{1}$ Oman Medical College, Oman

${ }^{2}$ Al Bushra Medical Specialty Complex, Athaiba Muscat-Sultanate of Oman, Oman

Submission: August 20, 2017 ; Published: August 31, 2017

*Corresponding author: Havagiray R Chitme, Oman Medical College, Baushar Campus, Muscat, Sultanate of Oman Post Box: 620; Postal Code: 130, Tel: 968-24504608; Email: hrchitme@gmail.com

\section{Abstract}

Background: It is well known that the women with polycystic ovary syndrome (PCOS) have reduced insulin sensitivity and increased insulin resistance. Objective of present study was to investigate the extent of change in insulin resistance and sensitivity in infertile women having history of PCOS by case control study using reliable clinical models among Omani population.

Methods: Present study was a hospital based case control study involving 132 Omani infertile women with an equal number of patients having PCOS as case and Non-PCOS as control. In this study we recorded family history in a data sheet; plasma LH and FSH was measured by Roche diagnostic electrochemiluminescence test, plasma insulin was measured by using ELISA methods and body fat and skeletal muscle composition was measured by bioelectrical impedence method. The homeostatic model for insulin resistance (HOMA), fasting insulin resistance (FIR) and Insulin sensitivity was computed by QUICKI method.

Results: A significant level of correlation of incidence in PCOS was noted in patients having family history of obesity, DM-II and PCOS at different levels. PCOS patients were noted with higher fasting plasma glucose level ( $\mathrm{p}<0.001,101.18 \mathrm{vs.} 90.17 \mathrm{mg} / \mathrm{dL}$ ), fasting plasma insulin $(\mathrm{P}<0.01,41.52 \pm 29.45$ vs. $24.64 \pm 16.39 \mu \mathrm{IU} / \mathrm{mL})$, fasting insulin resistance $(\mathrm{p}<0.001,169.63$ vs. 91.85), HOMA index ( $<<0.001,10.25 \pm 7.5 \mathrm{vs}$. $6.04 \pm 4.4$ ) and lower QUICKI ( $<<0.001,0.467 \pm 0.021$ vs. $0.487 \pm 0.02$ ) compared to control. Plasma LH level in PCOS was 9.7 vs. $5.54 \mathrm{mIU} / \mathrm{mL}$ and FSH was 7.4 vs. $5.9 \mathrm{mIU} / \mathrm{mL}$ of control group. The skeletal muscle to fat ratio was lower ( $<<0.001,35.72 \pm 9.19$ vs. $44.25 \pm 13.02$ ) compared to control.

Conclusion: We conclude that infertile women with PCOS have comparatively higher insulin resistance, lower sensitivity to insulin with decreased skeletal muscle mass to total body fat compared to previous studies involving women with PCOS only. However, further studies are recommended by involving more number of patients, hospitals and regions for concrete outcomes and recommendations for practice.

Keywords: PCOS; HOMA; QUICKI; Insulin resistance; Insulin sensitivity; Skeletal muscle ratio; Oman

\section{Introduction}

Polycystic ovary syndrome (PCOS) is one of the most common and complex endocrine disorders affecting 10 to $15 \%$ of females in reproductive age [1]. It is often characterized by menstrual irregularities, oligo or an ovulation, acne, hirsutism, hyperandrogenism and polycystic ovaries leading to an increase in risk for infertility [2,3]. In recent years about $50-70 \%$ of PCOS patients have glucose intolerance and insulin resistance responsible for multifactorial, heterogeneous and complex complications $[4,5]$. Incidence of PCOS is also linked to family history of diabetes mellitus -II and PCOS which further adds genetic factor in its occurrence [6]. It is well recognized that metabolic abnormalities in PCOS is majorly associated with increased basal glucagon and insulin due to parasympathetic stimulation of pancreatic islet cells5. Hyperglycemia stimulated excess, sustained hyper insulinemia is likely to precede to insulin resistance long before the appearance of clinical manifestations $[4,7]$. Development of insulin resistance in PCOS is proven to involve decreased glucose transport of adipocytes, decreased insulin receptor stimulation and hepatic clearance of insulin, increased pancreatic sensitivity and altered steroidogenesis $[8,9,10]$. Development of insulin resistance is a complex interaction of metabolic and pro-inflammatory mediators leads to defect in insulin binding to its receptor or to changes in insulin signal transmission $[4,11]$. On the other hand hyper insulinemia 
is believed to stimulate secretion of androgen in ovarian and adrenal glands leading to an increase in androgen levels followed by increased GnRH pulse frequency8. Persistent pulsating GnRH increase LH secretion consequently stimulating ovarian theca cells and relative decrease in FSH secretion [12].

Several studies have linked differences in pathogenesis of PCOS to different ethnic groups, familial and genetic predisposition [13]. A study on prevalence of diagnosed PCOS cases among women in Oman is similar to that of other countries however relationship between insulin activity and PCOS among infertile women is not yet studied [14]. We hypothesize that most reliable homeostasis model assessment (HOMA-IR) of insulin resistance supported by inverse factor quantitative insulin sensitivity check index (QUICKI), and fasting serum glucose to insulin ratio [15], will assist in understanding the basic mechanism and difference in activity of insulin in infertile women with PCOS and without PCOS. Primary objective of the present study was to investigate whether there is any difference in insulin resistance and sensitivity and to what extent in infertile PCOS and non-PCOS women.

\section{Research Methodology}

\section{Study design and participants}

Present study was a clinical case control hospital based. Sample size was calculated based on the fact that about 150 new patients make visit to selected hospital per six months for infertility treatment. Considering $5 \%$ margin of error, two-sided $95 \%$ confidence level with a power of $80 \%$ and $50 \%$ response distribution the sample size calculated to be 109 . Hence, we considered 132 total cases of which 66 PCOS cases and 66 non-PCOS as control matching in age and female infertility. Female infertility was defined as the failure to conceive fertility after a year of regular unprotected sexual intercourse. Women diagnosed with PCOS defined in accordance to Rotterdam criteria [16]. Criteria of exclusion include women with hypothyroidism, hyperthyroidism, liver failure, hyperprolactinemia, adrenal hyperplasia, diabetes, women receiving care with oral contraceptives, hypoglycaemics and anti-dyslipidaemics. Both group of patients visiting the study centre Al Bushra Medical Specialty Complex, Muscat - Oman were selected randomly.

\section{Materials}

In this study we used ELISA Insulin kits purchased from Wuhan Fine Biotech Co Ltd., China to estimate plasma insulin level, Plasma LH and FSH were estimated by using Electro chemiluminescence based Roche diagnostic kits. Skeletal muscle ratio and total body fat percentage were measured by using Omron HBF 375 Krada Scan Body Composition Monitor - Body Fat Analyzer22.

\section{Family History Influencing Incidence of PCOS}

We developed a data sheet to record obesity, diabetes mellitus-II, and PCOS history of patient's father, mother, sister, brother and others.

\section{Insulin Activity}

The overnight fasting plasma insulin level was measured by using ELISA Insulin kit by following the detailed manufacturer's instructions. The homeostatic model for insulin resistance (HOMA) was calculated by the formula glucose $(\mathrm{mg} / \mathrm{dL}) \mathrm{x}$ insulin $(\mathrm{mU} / \mathrm{mL}) / 405$, fasting insulin resistance percentage was = (25 x Glucose/Insulin); Insulin sensitivity was determined by QUICKI method as QUICKI = [1/(log Ins + log Glu] [17]. Plasma LH and FSH was measured by using Roche Diagnostics, Germany diagnostic kits.

\section{Skeletal Muscle and Body Fat Composition}

Body fat and skeletal muscle composition was measured by following the instructions supplied by Omron Body Composition analyser. The skeletal muscle ratio was calculated by the formula (100 x skeletal muscle mass/body weight) whereas body fat percentage was computed by using the formula (100 x body fat mass/body weight) $[18,19]$.

\section{Medical Ethics}

Study was initiated after seeking permission from Institutional Ethics Committee as well as the clinic. The study involves only those patients who signed a letter of consent to participate after specifying objectives, assurance of privacy, anonymity and confidentiality. All used and unused plasm specimens were sensibly disposed according to the biosafety and medical guidelines followed at clinic.

\section{Statistical Analysis}

The information collected from laboratory and data sheet were entered directly into SPSS version 23 (SPSS Inc. Chicago, IL, USA) and analyzed by using descriptive statistics such as mean and standard deviation for continuous numerical data, and for categorical data percentage-frequency distribution were used. Mean between groups were compared with the test and medians between them compared with the post-hoc Tuckey's test. Logistic regression were used to correlate insulin resistance and other factors. All findings are adjusted for covariates and logistic regression model was checked for collinearity. P values less than 0.05 were considered as statistically significant.

\section{Results}

\section{Family History Influencing Incidence of PCOS}

Our results indicate that family history having obesity, DMII + obesity, DM-II + PCOS, and DM-II + obesity+ PCOS have a different level of influence on incidence of PCOS compared to control group of patients. There is a highly significant $(p<0.001)$ level of correlation in incidence of PCOS in patient having a family history of obesity, (DM-II + Obesity), and (DM-II + PCOS). Most common correlation was noted in a women having a history of PCOS in mother. We observed that $22.72 \%$ of PCOS cases have family history of obesity, whereas control group were having $7.57 \% .16 .67 \%$ of PCOS cases were having family history of DMII + obesity whereas in control group it was $6.06 \%$ (Table $1 \&$ 
Figure 1). These results indicates that positive family history with metabolic disorder such as diabetes mellitus-II, PCOS and obesity increase the risk for PCOS. Odds Ratio for PCOS with family history of PCOS and obesity was 1.445 and 1.823 times

Table 1: Family History Influencing Incidence of PCOS

\begin{tabular}{|c|c|c|c|c|}
\hline \multirow{2}{*}{ Family History } & \multirow{2}{*}{ Control (\%) } & \multirow{2}{*}{ Case (\%) } & \multicolumn{2}{|c|}{ 95\% Confidence Interval } \\
\cline { 3 - 5 } & & & Lower & Upper \\
\hline DM-II & 34.84 & 33.33 & 1.336 & 2.486 \\
\hline Obesity & 7.57 & $22.72^{* * *}$ & 0.961 & 2.173 \\
\hline PCOS & 6.06 & 6.06 & 1.368 & 3.979 \\
\hline DM-II + Obesity & 6.06 & $16.67^{* * *}$ & 0.951 & 1.995 \\
\hline DM-II + PCOS & - & $6.06^{* * *}$ & 1.654 & 6.514 \\
\hline DM-II + Obesity + PCOS & 1.52 & 1.52 & & \\
\hline
\end{tabular}

Data was analyzed by multivariate analysis, OR, $95 \% \mathrm{Cl}$ and $p$ value ${ }^{* * *} p<0.001$.

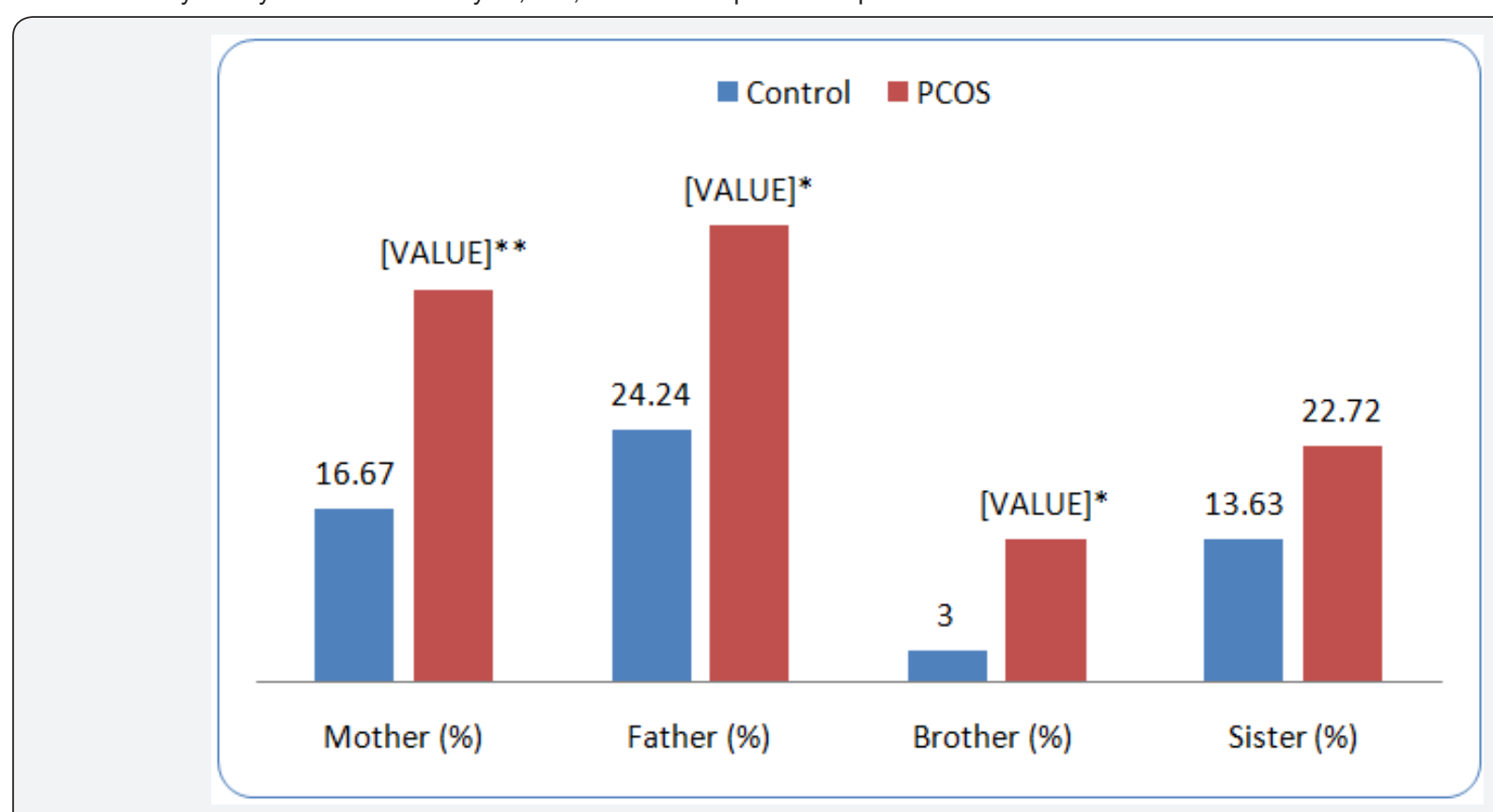

Figure 1: Family History Influencing Incidence of PCOS.

${ }^{* *}$ Pearson Chi-Square test shows very significant association at the 0.01 level (2-tailed)

*Pearson Chi-Square test shows very significant association at the 0.05 level (2-tailed)

\section{Insulin Activity}

Significantly $(\mathrm{p}<0.001)$ higher fasting plasma level of glucose was found in PCOS cases compared to normal. The mean fasting plasma glucose for control group was $90.17 \mathrm{mg} / \mathrm{dL}$ compared to $101.18 \mathrm{mg} / \mathrm{dL}$ in PCOS. The plasma insulin was very significantly $(\mathrm{P}<0.01)$ higher in PCOS than the control. Fasting insulin resistance in control group was 91.85 significantly $(\mathrm{p}<0.001)$ lower than 169.63 of PCOS group. Similarly, HOMA index in patients with PCOS was 10.25 \pm 7.5 significantly $(\mathrm{p}<0.001)$ higher

Table 2: Quantitative Analysis of Hormonal and Metabolic factors in Control and patients with PCOS

\begin{tabular}{|c|c|c|c|}
\hline \multirow{2}{*}{ Factors } & Study Group & Case \\
\cline { 2 - 4 } & Control & $101.18 \pm 15.79^{* * *}$ & \multirow{2}{*}{ Significance } \\
\hline Glucose $(\operatorname{mean}+\mathrm{SD})(\mathrm{mg} / \mathrm{dL})$ & $90.17 \pm 13.66$ & $41.52 \pm 29.45^{* *}$ & $\mathrm{P}<0.001$ \\
\hline Insulin $(\mu \mathrm{IU} / \mathrm{mL})$ & $24.64 \pm 16.39$ & $\mathrm{P}<0.01$ \\
\hline
\end{tabular}

than the control group of patients $(6.04 \pm 4.4)$. Quantitative insulin sensitivity check index (QUICKI) in PCOS patients was significantly $\mathrm{p}<0.001$ lower to $0.467 \pm 0.021$ compared to $0.487 \pm 0.02$ of control group. However, there is no significant difference in glucose/insulin ratio in PCOS and non-PCOS group of patients. Plasma LH level for control group was $5.54 \mathrm{mIU} /$ $\mathrm{mL}$ and FSH was $5.9 \mathrm{mIU} / \mathrm{mL}$ insignificantly lower than in PCOS cases compared to $\mathrm{LH}$ of $9.7 \mathrm{mIU} / \mathrm{mL}$ and $\mathrm{FSH}$ of $7.4 \mathrm{mIU} / \mathrm{mL}$ in control group (Table 2). 
Journal of Gynecology and Women's Health

\begin{tabular}{|c|c|c|c|}
\hline Glucose/ Insulin ratio & $5.32 \pm 3.43$ & $4.28 \pm 5.68$ & $\mathrm{P}>0.05$ \\
\hline LH(mIU/mL) & $5.54 \pm 5.76$ & $9.7 \pm 8$ & $\mathrm{P}>0.05$ \\
\hline FSH(mIU/mL) & $5.9 \pm 0.28$ & $7.4 \pm 3.32$ & $\mathrm{P}>0.05$ \\
\hline LH/ & $1.43 \pm 0.83$ & $1.34 \pm 0.92$ & $\mathrm{P}>0.05$ \\
\hline FSH Ratio & & & \\
\hline QUICKI & $0.487 \pm 0.02$ & $0.467 \pm 0.021^{* * *}$ & $\mathrm{P}<0.001$ \\
\hline Fasting Insulin Resistance \% & $91.85 \pm 63.73$ & $169.63 \pm 121.79^{* * *}$ & $\mathrm{P}<0.001$ \\
\hline HOMA & $6.04 \pm 4.4$ & $10.25 \pm 7.5^{* * *}$ & $\mathrm{P}<0.001$ \\
\hline
\end{tabular}

Quantitative insulin sensitivity check index (QUICKI), Homeostasis model assessment (HOMA) of Insulin Resistance. ${ }^{* *} \mathrm{p}<0.001,{ }^{* *} \mathrm{p}<0.01$.

\section{Comparative Analysis of Skeletal Muscle Ratio}

Results shows that the skeletal muscle to fat ratio was significantly $(\mathrm{p}<0.001)$ lower $(35.72 \pm 9.19)$ in PCOS cases compared to $44.25 \pm 13.02$ in normal control revealing defects in insulin signaling. A significant negative correlation ( $\mathrm{r}-0.33$, $\mathrm{p}<0.01$ ) was seen between number of ovarian cysts and skeletal muscle ratio.

\section{Discussion}

Present study was envisaged with an objective to assess insulin resistance and sensitivity in infertile PCOS and non-PCOS infertile women. The objectives were achieved by most widely used research tools such as HOMA-IR, QUICKI, FIR, skeletal muscle ratio, total body fat and also estimating the level of $\mathrm{LH}$ and FSH14. Results obtained in this study are almost higher than reported by earlier studies involving only PCOS without infertility [20]. Results in our study shown significant level of incidence of PCOS in patients having family history of obesity, DM-II and PCOS at different levels. Most common correlation was noted in a women having a history of PCOS in mother. These results could be due to the fact that insulin resistance in these patients may be reprogrammed and inherit some of these features of their mothers [21]. Odds Ratio for PCOS with family history of PCOS and obesity was more than control group especially with history of mother compared to other family members. These results are in-line with the study describing decrease in insulin sensitivity only in woman with PCOS and family history of DM-II5. Previous studies reported a highly significant correlation in incidence of PCOS in patient having family history of diabetes mellitus - II, obesity and PCOS [17,22,23].

A prospective cohort of 118 hyperandrogenic women with PCOS who were followed from the age of [20-25], years at 5 year intervals for 20 years has shown a higher insulin and lower QUICKI [24]. Results obtained in our study clearly shows hyperglycemia followed by hyperinsulinemia in PCOS patients. Our results are in line with the study carried out in India among PCOS women from Delhi and Srinagar [25]. Mean values of FPG, FPG/insulin ratio, QUICKI indexes and HOMA were significantly higher among PCOS cases when compared with controls similar to the study reported earlier [26] and substantiating the very recently published research article [27,5].

The results from our study demonstrate that the wellestablished abnormalities in insulin action in infertile PCOS patients could be due to defect in glucose uptake and glycogen synthesis in skeletal muscles. It has been demonstrated that the degree of insulin resistance in young women with PCOS was similar to that seen in middle-aged patients with type 2 diabetes [9]. A significant negative correlation $(\mathrm{r}-0.33, \mathrm{p}<0.01)$ was seen between number of ovarian cysts and skeletal muscle ratio. Insulin resistance in PCOS is associated with skeletal muscle activity as it is the major site of insulin mediated glucose disposal and ability to synthesize, convert and degrade androgens. Preserving insulin sensitivity depends on transport of glucose in myotubes [28].

We recommend the readers to consider the limitations of this study as it involves only infertile Omani women, selected randomly from a single hospital and hospital based population as control group. It is also important to note that the study was conducted only for six months by involving limited number of patients. The insight gained from this study have improved our understanding of the difference in activity of insulin in infertile women with PCOS and without PCOS. This study outcome can form the basis to provide concept in management of PCOS in infertile patients. Present study is an extension of previous studies $[29,30]$, forming the basis for further studies, which can lead to the development of treatment that more directly targets higher insulin resistance, and hence reduce the risk of developing insulin resistance complications due to PCOS in infertile women.

\section{Conclusion}

Based on the results of this case control study we conclude that infertile women with PCOS and non-PCOS have higher insulin resistance, lower sensitivity to insulin with decreased skeletal muscle mass to total body fat. The insulin resistance seen in this study could be an inherited from family members having history of obesity, diabetes type II and PCOS in particular from mother. However, we recommend further studies by involving more patients, hospitals and regions of Oman for an extended period for concrete outcomes and their possible implementation in practice.

\section{References}

1. Burchall G, Linden MD, Teede H, Piva TJ (2011) Hemostatic abnormalities and relationships to metabolic and hormonal status in polycystic ovarian syndrome. Trends Cardiovasc Med 21(1): 6-14.

2. Nisenblat V, Norman RJ (2009) Androgens and polycystic ovary syndrome. Curr Opin in Endocrinol Diabetes Obes 16(3): 224-231. 
3. Ramaswamy S, Grace C, Mattei AA, Siemienowicz K, Brownlee W, et al. (2016) Developmental programming of polycystic ovary syndrome (PCOS): prenatal androgens establish pancreatic islet $\alpha / \beta$ cell ratio and subsequent insulin secretion. Sci Rep 6(1): 27408.

4. Bostancı MS, Akdemir N, Cinemre B, Cevrioglu AS, Özden S, et al. (2015) Serum irisin levels in patients with polycystic ovary syndrome. Eur Rev Med Pharmacol Sci 19(23): 4462-4468.

5. Allahbadia GN, Merchant R (2011) Polycystic ovary syndrome and impact on health. Middle East Fertility Society Journal 16(1): 19-37.

6. Vrbíková J, Grimmichová T, Dvoráková K, Hill M, Stanická S, et al. (2008) Family history of diabetes mellitus determines insulin sensitivity and beta cell function in polycystic ovary syndrome. Physiol Res 57(4): 547-553.

7. Gültepe İ, Başaranoğlu M, Süleymanoğlu Y, Başaranoğlu G, Beyazıt F (2016) Ovaries are more vulnerable than hepatocytes for insulin resistance and hyperinsulinemia. Turk J Gastroenterol 27(1): 62-67.

8. T Mutib M, B Hamdan F, R Al Salihi A (2014) INSR gene variation is associated with decreased insulin sensitivity in Iraqi women with PCOs. Iran J Reprod Med 12(7): 499-506.

9. Sacchinelli A, Venturella R, Lico D, Di Cello A, Lucia A, et al. (2014) The Efficacy of Inositol and N-Acetyl Cysteine Administration (Ovaric HP) in Improving the Ovarian Function in Infertile Women with PCOS with or without Insulin Resistance. Obstet Gynecol Int 2014(2014): 141020 p. 5 .

10. Højlund K (2014) Metabolism and insulin signaling in common metabolic disorders and inherited insulin resistance. Dan Med J 61(7): B4890.

11. De Leo V, Tosti C, Cappelli V, Morgante G, Cianci EA (2014) Combination inositol and glucomannan in PCOS patients. Minerva Ginecol 66(6): 527-533.

12. Ramezani TF, Daneshpour M, Hashemi S, Zarkesh M, Azizi F (2013) Relationship between polymorphism of insulin receptor gene, and adiponectin gene with PCOS. Iran J Reprod Med 11(3): 185-194.

13. Garruti G, de Palo R, Rotelli MT, Nocera S, Totaro I, et al. (2014) Association between follicular fluid leptin and serum insulin levels in non-overweight women with polycystic ovary syndrome. Biomed Res Int 2014(2014): 980429 p. 7.

14. Al Khaduri M, Al Farsi Y, Al Najjar TAA, Gowri V (2014) Hospital-based prevalence of polycystic ovarian syndrome among Omani women. Middle East Fertility Society Journal 19(2): 135-138.

15. Ghaffarzad A, Amani R, Mehrzad SM, Darabi M, Cheraghian B (2016) Correlation of Serum Lipoprotein Ratios with Insulin Resistance in Infertile Women with Polycystic Ovarian Syndrome: A Case Control Study. Int J Fertil Steril 10(1): 29-35.

16. Rotterdam ESHRE/ASRM-Sponsored PCOS Consensus Workshop Group (2004) Revised 2003 consensus on diagnostic criteria and longterm health risks related to polycystic ovary syndrome. Fertil Steril 81(1): 19-25.

17. Katz A, Nambi SS, Mather K, Baron AD, Follmann DA, et al. (2000) Quantitative insulin sensitivity check index: a simple, accurate method for assessing insulin sensitivity in humans. J Clin Endocrinol Metab 85(7): 2402-2410.
18. Ezeh U, Pall M, Mathur R, Azziz R (2014) Association of fat to lean mass ratio with metabolic dysfunction in women with polycystic ovary syndrome. Hum Reprod 29(7): 1508-1517.

19. Omron Healthcare Co. Ltd., 53, Kunotsubo, Terado-Cho, Muco, Kyoto, 617-0002, Japan.

20. Goodman NF, Cobin RH, Futterweit W, Glueck JS, Legro RS, et al. (2015) American Association of Clinical Endocrinologists, American College of Endocrinology and Androgen Escess and PCOS Society Disease State Clinical Review: Guide to the Best Practices in the Evaluation and Treatment of Polycystic Ovary Syndrome-Part 2. Endocr Pract 21(12): 1415-1426.

21. Sir-Petermann T, Echiburú B, Crisosto N, Maliqueo M, Bravo FP(2016) Metabolic Features Across The Female Life Span In Women With PCOS. Curr Pharm Des 22(36): 5515-5525.

22. Lerchbaum E, Schwetz V, Giuliani A, Obermayer-Pietsch B (2014) Influence of a positive family history of both type 2 diabetes and PCOS on metabolic and endocrine parameters in a large cohort of PCOS women. Eur J Endocrinol 170(5): 727-739.

23. Lystedt E, Westergren H, Brynhildsen J, Lindh-Astrand L, Gustavsson J, et al. (2005) Subcutaneous adipocytes from obese hyperinsulinemic women with polycystic ovary syndrome exhibit normal insulin sensitivity but reduced maximal insulin responsiveness. Eur J Endocrinol 153(6): 831-835.

24. Carmina E, Campagna AM, Lobo RA (2013) Emergence of ovulatory cycles with aging in women with polycystic ovary syndrome (PCOS) alters the trajectory of cardiovascular and metabolic risk factors. Hum Reprod 28(8): 2245-2252.

25. Ganie MA, Marwaha RK, Dhingra A, Nisar S, Mani K, et al. (2016) Observation of phenotypic variation among Indian women with polycystic ovary syndrome (PCOS) from Delhi and Srinagar. Gynecolo Endocrinol 32(7): 566-570.

26. Caglar GS, Kahyaoglu I, Pabuccu R, Demirtas S, Seker R (2013) AntiMullerian hormone and insulin resistance in classic phenotype lean PCOS. Arch Gynecol Obstet 288(4): 905-910.

27. Svendsen PF, Nilas L, Nørgaard K, Jensen JE, Madsbad S (2008) Obesity, body composition and metabolic disturbances in polycystic ovary syndrome. Hum Reprod 3(9): 2113-2121.

28. Eriksen MB, Glintborg D, Nielsen MF, Jakobsen MA, Brusgaard K, et al. (2014) Testosterone treatment increases androgen receptor and aromatase gene expression in myotubes from patients with PCOS and controls, but does not induce insulin resistance. Biochem Biophys Res Commun 451(4): 622-626.

29. Chitme HR, Al Azawi EK, Al Abri AM, Al Busaidi BM, Salam ZKA, et al. (2017) Anthropometric and body composition analysis of infertile women with polycystic ovary syndrome. Journal of Taibah University Medical Sciences 12(2): 139-145.

30. Chitme HR, Al Azawi EK, Al Abri AM, Al Busaidi BM, Salam ZKA, et al. (2017) Correlation between number of ovarian cysts in polycystic ovary syndrome and anthropometric and biochemical factors. J Basic Clin Pharma 8: 107-110. 
This work is licensed under Creative Commons Attribution 4.0 Licens

DOI: $10.19080 / J G W H .2017 .06 .555700$
Your next submission with Juniper Publishers will reach you the below assets

- Quality Editorial service

- Swift Peer Review

- Reprints availability

- E-prints Service

- Manuscript Podcast for convenient understanding

- Global attainment for your research

- Manuscript accessibility in different formats

( Pdf, E-pub, Full Text, Audio)

- Unceasing customer service

Track the below URL for one-step submission https://juniperpublishers.com/online-submission.php 